\title{
A comunicação e a construção de sentidos na formação de professores: um trabalho a várias mãos
}

\author{
Communication and meaning construction in teacher education: work \\ by many hands
}

Tania Maria Esperon Porto*

Universidade Federal de Pelotas

Maristani Polidori Zamperetti**

Universidade Federal de Pelotas

Lourdes Helena Rodrigues dos Santos***

Universidade Federal de Pelotas

Resumo Este texto apresenta um recorte de três processos de pesquisas realizadas em contextos diferentes: duas escolas públicas de ensino fundamental e médio e uma universidade pública, tendo por confluência a experiência de comunicação, partilha e construção colaborativa de sentidos vividas por nós, educadores-pesquisadores. Dialogamos com os docentes e os meios de comunicação e suas linguagens. Vivemos e investigamos processos de formação docente com metodologias comunicacionais, as quais tornaram possível realizar experiências concretas, fazer questionamentos e reflexões sobre o cotidiano docente, tratados à luz do referencial teóriço da educação e comunicação. As práticas comunicacionais proporcionaram experienciar o mundo, desvelar sentidos dos docentes, permitindo uma interação entre os sujeitos e seus respectivos contextos. Trabalhar a várias mãos, é prover meios para enfrentar situações complexas que, individualmente, poderíamos não conseguir administrar.

PALAVRAS-ChaVE: Construção Colaborativa, Formação de Professores, Sentido.

Abstract This text aims to bring a crop of three processes of research conducted in different contexts: two public schools in elementary and high school and a public university, with the confluence of the experience of communication, sharing and collaborative construction of meaning experienced by us, educators and researchers. We talked to teachers and the media and their languages. We have lived and investigated processes of teacher training in communicative methodology, which made it possible to create experiences, to ask questions and reflections about everyday teaching, treated in the light of theoretical education and communication. The communication practices provided practical experiences of the world, reveal directions of teachers, allowing an interaction between subject and their contexts. Working among several different people is to provide means to cope with complex situations that individually we can not manage.

KEYWORDS: Collaborative Construction, Teaching Formation, Sense. 
É que pensamos que todas as coisas boas da Vida bem podiam ser de toda a Gente. Bem podiam ser, o tempo todo, de todas as Pessoas. De todos nós. Assim: de todas as mulheres e de todos os homens, de todas as crianças, de todos os velhos, e até de todos os adultos. De todo Mundo, ao mesmo tempo. De toda a Gente de todos os lugares do Mundo... Então o que é bom de viver seja um bem para todo Mundo. (BRANDÃO, 2004, p. 5, grifos do autor)

Este é um texto que se propõe a trazer algumas reflexões sobre processos de pesquisas vividos por três grupos de pesquisa em três contextos diferentes: duas escolas públicas de ensino fundamental e médio e uma universidade pública (todos em uma cidade do interior do RS), tendo, por convergência, a experiência de comunicação, partilha e construção colaborativa de sentidos vividas por todos nós, educadores que pesquisam e não por pesquisadores que eventualmente educam. Este aspecto se faz presente logo na introdução do texto, uma vez que justifica as escolhas e os caminhos adotados, entremeados com práticas de ensinar e aprender e definidos pelas necessidades dos contextos nos quais aconteceram. Assim, o texto escolhido como epígrafe justifica-se, pois com o recorte das pesquisas que trazemos, pretendemos compartilhar com Gente de todo mundo, nossas aprendizagens com Gente de todos os lugares por onde vimos realizando as pesquisas.

É um texto que pretende compartilhar algumas descobertas, as quais, apesar dos diferentes sujeitos envolvidos (professores de ensino fundamental, médio e universitário), evidenciaram, ao longo de partilhas concretas, perguntas e dilemas cotidianos tratados à luz do referencial teórico de educação e comunicação, tendo como suporte autores que nos ajudam na construção de uma pedagogia com os meios de comunicação. $\mathrm{O}$ trabalho em nossos grupos de pesquisa inclui meios e tecnologias, como programas de TV, vídeo, cenas teatrais, literatura, materiais de artes plásticas, entre outros. Dialogamos com os meios de comunicação e suas linguagens, em vez de falar deles. Fortalecemos nosso referencial teórico com autores, tais como Brandão (2003), Gutiérrez (1984, 2001, 2003), Penteado (1998, 2002, 2010) e Porto (2003, 2006, 2010).

Esse referencial permite-nos perceber a complexidade dos processos de ensinar e aprender e a valorização do exercício de comunicação escolar que, no entender de Penteado (2010), consiste em desenvolver a alteridade necessária ao desempenho docente que possibilita colocar-se no lugar do outro: do aluno que ele foi um dia, do aluno atual e do aprendiz que ele foi na condição de docente. Postura semelhante a esta encontramos em Gutiérrez (1984, 2003), para o qual o trabalho não se constrói com locutores e ouvintes, mas com interlocutores, ou seja, com sujeitos que se comunicam em redes (através de tecnologias e meios de comunicação), constroem relações em gestões colaborativas, rejeitando o autoritarismo e adotando a interatividade pedagógica.

Nas relações que construímos com as pessoas, vamos descobrindo informações, saberes, peculiaridades além de construir teorias, práticas de ensino e de pesquisa que contribuem com nossa formação individual - como professores-pesquisadores - e convivência com os outros - alunos, professores e pesquisadores.

As pesquisas, que aqui vamos relatar, tiveram como objetivos conhecer os professores em relação às vivências pessoais e profissionais, investigar suas relações 
com os meios de comunicação e metodologias comunicacionais e imagéticas, além de perceber posturas de professores reflexivo-investigativos. É importante salientar que o recorte que trazemos não evidencia o trabalho com todos os objetivos percorridos nas pesquisas.

Reforçando a necessidade de conhecermos práticas e saberes docentes presentes na escola e na universidade, percebemos a necessidade de trazermos dados de pesquisas que vinculassem estes dois espaços de formação de professores: a universidade e a escola ${ }^{1}$, a partir dos casos específicos relatados. Assim, antes de relatar os dados, tanto da universidade como da escola, é relevante pontuar que um paradigma de trabalho, nesses contextos, valoriza e respeita o vínculo entre dois espaços distintos com tarefas e responsabilidades distintas, mas voltados para um mesmo objetivo: ensinar e aprender.

\section{Espaços de atuação e formação docente - abordagens me- todológicas}

Para Porto (2010), o reconhecimento da existência de saberes que se constroem na escola remete-nos à percepção da necessidade de vinculação entre os dois espaços de atuação e formação docente: universidade e escola.

A escola e a universidade produzem movimentos e são resultantes deles. Essas instituições não são lineares e nem mecanicistas [...] são espaços de socialização, de encontros, convivência e colaboração com os outros. Assim, a educação tanto na escola, quanto na universidade envolve (ou deveria envolver) espaços comunicativos que mobilizem os sujeitos em embates e interações para a (res)significação do comum e para a construção da unidade (individual e social). (PORTO, 2010, p. 97)

Desta forma, os espaços comunicativos - tanto na escola quanto na universidade - ajudam os professores na reflexão, adesão e apoio às causas do grupo, em busca da compreensão e transformação da realidade em estudo.

O paradigma teórico e investigativo escolhido ancora-se em uma teoria pedagógico-comunicacional que está em construção, é processual e interdiscursiva. Este paradigma evidencia a necessidade do entendimento dos processos de interdependência e interatividade entre os sujeitos e os processos educativos e sociais presentes na complexidade da vida atual. Parece haver um consenso de que paradigmas globalizantes e hegemônicos não conseguem mais dar respostas para as realidades educacionais que apresentam contextos e valores sociais diversos. Afinal, é no embate com a realidade escolar que as antigas certezas caem por terra e exigem, cada vez mais, a busca e o entrecruzamento de saberes.

Nas metodologias vivenciadas em nossas pesquisas (entendidas como pesquisa-participante), o caráter de participação, colaboração e interlocução entre os sujeitos foi uma constante. Professores e alunos, pesquisadoras e pesquisados participaram de todas as etapas do processo, não só com leituras e estudos epistemológicos, mas com intervenção em situações consideradas problemas ou merecedoras de estudos e investigação, para a busca de reflexões e/ou mudanças. Vivemos e investigamos processos de formação docente com metodologias comunicacionais, as quais têm nos levado a diferentes caminhos dentro dos espaços educativos. 
Concordamos com Brandão (2003), ao associar metodologias com "pontes" que constituem caminhos de mão dupla e que convergindo para uma única direção, tornam-se uma múltipla praça simbólica de convergências, diferenças e divergências. Para o autor, não há teorias "únicas ou melhores [...] as diferentes abordagens intersubjetivas, qualitativas e participantes são modalidades de abertura de uma escuta sensível a essas dimensões do pensado e do vivido cotidiano" (2003, p. 108, grifos do autor).

Ao utilizar os meios de comunicação e as metodologias dialógico-participativas para além de mera ilustração do escrito/falado, possibilitamos abordar novas sensibilidades, respeitando necessidades e interesses dos sujeitos imersos no mundo audiovisual e, consequentemente, sensorial e imagético. De outra forma, é interessante observar a importância da utilização dos meios de comunicação, metodologias comunicacionais e ferramentas artísticas como instrumentos de pesquisa, seja para aproximação e interação entre pessoas, seja para levantar dados. Os meios, quando usados com esses fins, integram os sentidos, a emoção, a intuição e a razão, além de envolverem diferentes linguagens que facilitam a expressão dos sujeitos e o desocultamento de saberes, significados, emoções e conhecimentos presentes em suas vivências.

Para Brandão, a pesquisa realizada no coletivo "de mãos" pressupõe experiências que têm a ver com "vivências conscientes", bem mais do que com "experimento controlado". Para o autor, a experiência sugere uma vocação de sentidos mais existencial que epistemológico, ou seja, mais de vivência do que de ciência. A experiência da pesquisa a várias mãos sugere ações realizadas "num continuum de vidas dedicadas a construir mundos sociais por meio da criação solidária de saberes" (2003, p. 18).

Pesquisas de formação docente com meios de comunicação e metodologias comunicacionais vão além de relações lógico-cognitivas entre sujeitos. Privilegiam a comunicação afetiva, permitindo-lhes um "mergulho" nas sensações proporcionadas ao contato com elas. No entender de Babin, os meios de comunicação são portas de entradas para os conhecimentos. A "emoção liga-se diretamente à excitação sensorial [...] situa-se entre o psíquico e o físico, e comporta uma forte tonalidade afetiva [...] a emoção modifica o corpo todo" (1993, p. 24). Ainda, de acordo com o autor, o principal efeito dos meios não é o de nos fazer aprender, mas o de, através das emoções, socializar os sujeitos.

A abordagem do conhecimento e o estabelecimento de relações, por meio de diferentes linguagens (imagética, sonora e corporal), trazem para os espaços educativos, as emoções, o humor, a ironia, os sentimentos. Pretendendo aproximar-se de uma fala "mais científica", as linguagens utilizadas, na maioria das vezes, pelos professores, afastam-se de seus interlocutores. Para Penteado (2002), cumpre-nos refinar o uso da linguagem oral e escrita com que tradicionalmente trabalhamos e explorar outras linguagens ainda distantes do contexto de pesquisa.

Assim, podemos perceber com os sentidos e compreender com a reflexão o que está acontecendo. Para Brandão, métodos "de investigação não antecedem mudanças do olhar ou de pontos de vista [...] mas podem ajudar para que isso aconteça" (2003, p. 97).

Para Gutiérrez (1984, 2003), a interlocução é um processo educativo que se define pela interação entre os sujeitos. É nessa relação intersubjetiva - construída 
em conjunto por professor e alunos, pesquisador e pesquisados - que emergem ideias, questionamentos, informações, dúvidas, que levam os sujeitos a reflexões, confrontos, superação de conflitos, decisões e resoluções. No coletivo de professores com os pares, esta situação nem sempre ocorre de forma natural. As pesquisas evidenciaram a necessidade de lideranças no grupo, definidas a priori ou legitimadas no processo, sempre com aceitação e inserção dos sujeitos que dele participam.

Segundo Porto (2003), o confronto e a análise de problemas pessoais e/ ou profissionais, de situações complexas e práticas, presentes no trabalho de equipe, pressupõe níveis de interdependência entre recursos, ideias, práticas e os sujeitos envolvidos. Assim, muitas vezes

[...] é necessário administrar crises e confrontos que surgem pelas oportunidades dadas aos docentes, de manifestarem seu ponto de vista e expressarem seus interesses, dificuldades e soluções encontradas. Estas situações aparecem com mais frequência com o conhecimento e interação que se estabelecem entre os sujeitos. (PORTO, 2003b, p. 7)

Para a autora, atitudes de admitir o erro, ouvir e analisar opiniões alheias e decidir em situações difíceis, originadas de conflitos e de "práticas já sacramentadas", são atitudes corajosas de que o coletivo de professores não pode prescindir. Assim, pensar nas consequências decorrentes das decisões tomadas implica em:

\begin{abstract}
assumir dimensões pessoais, profissionais, sociais e/ou políticas, como uma responsabilidade que nem todos os profissionais esperam ou estão preparados para assumir. É um caminho rico que põe em discussão diferentes contextos, situações, sentimentos e práticas individuais e coletivas. A aprendizagem no coletivo pressupõe movimento e provisoriedade. Sempre há algo para aprender. E se há algo para aprender, é porque os professores não sabem tudo e, estando abertos para ouvir e conversar com os colegas, seus conhecimentos estão em construção. (PORTO, 2003b, p. 7)
\end{abstract}

Assim, com esse entendimento de pesquisa colaborativa com meios e linguagens comunicacionais, trazemos alguns dados levantados nos ambientes escolares onde aconteceram as pesquisas relatadas.

As palavras de uma professora da Instituição 2 expressam as reflexões e as aprendizagens surgidas a partir dos conflitos e divergências no grupo:

[...] com o trabalho pedagógico coletivo temos a chance de compartilhar ideias que nos enriquecem muito, principalmente quando são conflitantes e divergentes. Muitas vezes, nos sentimos impotentes diante da realidade da escola que exige mudanças. Entretanto, o que fazemos juntas é dialogar, propor e construir experiências que possam motivar o outro a participar desta caminhada à procura de soluções dos problemas que nos angustiam. (Maria, Instituição 2)

Os percursos destas pesquisas sobre formação docente na universidade e na escola sugerem a necessidade de serem repensadas as práticas pedagógicas, em especial, através do trabalho coletivo, no qual a aprendizagem acontece em processos dinâmicos, conflituosos e provisórios, que envolvem conhecimentos em construção e diálogo entre 
os pares, conforme depoimento do sujeito da Instituição 2. Para Sandra essas oportunidades ampliam a capacidade de reflexão e de interação com os pares.

Essa experiência tem sido muito gratificante, além de prazerosa e muito educativa. A troca de conhecimento se dá de uma forma democrática e participativa. Há algumas dificuldades que aparecem de vez em quando, pois se trata de um processo que é construído aos poucos, e aprendemos muito, tanto com os erros como com os acertos. Muitas vezes, algumas certezas são desconstruídas, ficamos um pouco inseguras, mas logo encontramos um novo rumo e seguimos adiante. (Sandra, Instituição 2)

\section{Partilha de saberes, sentidos e experiências em trabalhos colaborativos}

Damiani, Porto e Schlemmer (2009), apontam a colaboração e a cooperação como elementos fundamentais no trabalho docente, embora não descartem a reflexão e o trabalho individuais.

A expressão trabalho pedagógico coletivo caracteriza-se pelo desenvolvimento de práticas pedagógicas que têm como foco a participação e envolvimento de professores e alunos, de pesquisadores e pesquisados no processo de construção de conhecimentos teórico/práticos, contemplando diálogos, análises, reflexões e trocas de saberes sobre as temáticas em estudo. Diante dos referenciais teóricos pesquisados para construção deste estudo, agregamos pesquisas, nas quais os autores aproximamse pelas expressões: trabalho colaborativo, trabalho em equipe, trabalho cooperativo, identificadas pelas características comuns e consonância com o trabalho coletivo por nós desenvolvido.

Para completar esse entendimento, agregamo-nos às ideias de Brandão (2003), ao explicar a palavra partilha e suas companheiras: compartilhar, coletivizar, socializar, conectar, interagir. Para o autor, o conhecimento humano a respeito das pessoas, da vida da sociedade e do mundo, por ser pensado, vivido e sentido, não pode ser, de modo algum, submetido à lógica mercantilista, ou seja, não pode ser comprado ou vendido. Partilhar em pesquisa é significativo, pois tais como outras dimensões da vida social,

a ciência e seus momentos de pesquisa são ou devem ser algo tão estranho quanto possível às teias da posse e do poder. Em outra relação bem diversa, elas devem realizar-se como algo integrado, tanto quanto possível, no círculo da reciprocidade. (2003, p. 19, grifos nossos.)

As vivências pedagógicas, quando olhadas à luz de um referencial teórico, tornam-se conhecimentos práticos adquiridos no cotidiano escolar, podendo colaborar para minimizar a dicotomia entre a vida pessoal e a vida profissional do professor, conforme depoimentos de professores das Instituições 2 e 3, os quais demonstram o prazer das aprendizagens no coletivo e de como isso é importante pra seu crescimento profissional.

Toda quarta-feira é considerada especial para mim. Chego na escola animada, participo ativamente das atividades conjuntamente com 
minhas outras colegas e com as alunas, e saio satisfeita com as descobertas feitas pelo grupo. É maravilhoso. Na busca do crescimento profissional é preciso inovar e desmistificar, e isso é o que estamos nos propondo com este trabalho. (Sônia, Instituição 2)

As dinâmicas provocaram uma profunda reflexão, interação do grupo e contribuíram para valorização pessoal e para perceber que não estou só. (Vera, Instituição 3)

A partilha de saberes e experiências em trabalhos colaborativos contribui para transformar as escolas em instituições de interesse e significação para professores, por proporcionar-lhes estímulos para transformações, nas práticas pedagógicas e percepção de novas formas de se constituírem professores.

Nas vivências comunicacionais de partilha e construção colaborativa experienciadas por nós, educadores-pesquisadores, encontramos formas significativas de ensino-aprendizagem que fizeram sentido para os sujeitos envolvidos na investigação. Para Gutiérrez, o sentido é o

eixo articulador dos processos educativos, [...] é motor do processo educativo e põe em jogo as capacidades do sujeito, desde a percepção de suas necessidades e problemas até a produção de soluções; da autoaprendizagem à interaprendizagem; das práticas da sua vida cotidiana à sua imersão social e política. (2001, p. 8)

Assim, nos movimentos empreendidos por nós, professores/pesquisadores, para encontrar sentido nas experiências com as pesquisas, nos deparamos com sentimentos e emoções decorrentes de perdas de sentido nas ações cotidianas dos professores. Isto está evidenciado no comentário de Elisa, ao se referir às significações dadas ao estudo e às relações estabelecidas no espaço escolar entre alunos, professores e demais profissionais, comparando com a realidade mais ampla fora da escola.

Me frustra essa coisa dos alunos não atingirem o mínimo que a gente consideraria ideal, né? Se é que existe ideal! Mas frustra mais as relações dentro da escola; e tem também aquele sentimento de impotência: a escola é um lugar do passado, eles não tem como gostar mesmo, não tem nada para agradar eles, né? Lá fora tem milhares de outras opções melhores do que a escola. (Elisa, Instituição 1)

Neste depoimento, percebemos, como consequência da perda de significado na vida escolar cotidiana, uma quase supressão dos sentidos nas vivências de professores e alunos, talvez como forma de evitar a angústia ou a reflexão sobre as ações dos docentes para superar a situação de frustação.

A educação é um processo de elaboração de sentidos para a vida, conhecimentos, relações, dentre outros. Como nos assegura Gutiérrez (2001), não são os conhecimentos, os saberes, as verdades e os valores verbalizados através de discursos que dão sentido à vida. O sentido não está nos planos de estudo, nem nos objetivos e nem no repasse de conteúdos, como relembra Roberta, trazendo à tona as lembranças da escolaridade e refletindo sobre sua construção de sentido; portanto o sentido está no que se vive, experimenta e constrói para além dos conteúdos estudados na escola. 
Com toda a sinceridade, se eu me reportar à vida dos nossos alunos naquele tempo, também eu não via sentido, eu sabia, por exemplo, que era preciso estudar, que eu só poderia me desenvolver intelectualmente se eu me mantivesse na escola, aprendendo. $\mathrm{O}$ sentido do conteúdo, eu não lembro de ter. Hoje, eu acho que tudo aquilo que me foi ensinado tem um significado importante, porque eu entendo como um processo necessário pra chegar onde eu estou, agora, como é que nós vamos trabalhar isso com o aluno, hoje eu não sei. Mas acho que [...] nós percebemos que as coisas se constroem. A palavra construção tem a ver [com] um processo que vai se agregando e se desenvolvendo até chegar num estágio que te dê autonomia. (Roberta, Instituição 1, grifos nossos)

Para Roberta, a construção pessoal acontece num continuum, quando o coletivo com os pares tem papel fundamental. Compartilhamos com Gutiérrez (2001) a ideia de que o sentido se constrói nas relações próximas e imediatas de cada pessoa, nos diferentes contextos nos quais ela vive, nos processos e relações significativas. $\mathrm{O}$ autor sustenta a ideia de que, quando damos sentido ao que fazemos, quando compartilhamos propósitos, quando impregnamos de sentido as práticas da vida cotidiana e compreendemos o sentido de tantas outras, estamos dando significado ao mundo que vivemos e ao que nos acontece nesse mundo. Desta forma, para o autor, o sentido

se faz e se refaz no fazer cotidiano, e é claro que o sentido, dentro da prática educativa, tem que ser pedagógico, porque requer um método e é consequência de estratégias e procedimentos pedagógicos. [Assim], ou promovemos uma aprendizagem com sentido, ou pelo contrário, impomos uma aprendizagem sem sentido. A aprendizagem com sentido forma protagonistas, seres para os quais todas e cada uma das atividades, todos e cada um dos conceitos significam algo para a própria vida. (GUTIÉRREZ, 2001, p. 12)

Está implícito, no conceito do autor o "protagonismo", que Roberta explica utilizando o termo "autonomia" para se referir ao sujeito que propõe ações, toma suas decisões, faz escolhas e dá significado às suas ações.

Situação semelhante a essa é apresentada por Porto (2006), ao afirmar que o diálogo e a reflexão permitem ao sujeito utilizar o pensamento como atribuidor de sentidos e significados em processos de convivência coletiva. Assim, percebemos os colegas através de vivências comunicacionais dialógicas e participativas de consideração ao outro que sente/pensa/age igual ou diferente de nós, pois é um processo de partilha consentida, de colaboração e solidariedade. "Nunca um processo de dominação-subordinação" (PENTEADO, 1998, p. 19). Para a autora, os sujeitos admitem a recusa, o ponto de vista diferente, são receptivos ao enfado e ao entusiasmo. É um processo que exige problematização e orienta-se pelo princípio da alteridade, considerando a presença do outro sensível e singular em cada atitude profissional.

Nos recortes das pesquisas que aqui trazemos, utilizamos meios de comunicação que possibilitam o diálogo, inter-relações, autoconhecimento e busca de sentido em nossos fazeres. A fala de Joana (Instituição 1) mostra a reflexão sobre os sentidos produzidos pela sua participação, no grupo da escola, ao assistir e discutir o vídeo-documentário "Janela da Alma". 
Quando a gente começou a ver o filme, [...] eu fiquei pensando: Puxa vida... O tempo que a gente para junto prá ver um filme? Isso faz tanta diferença pra gente, se pudesse ter esses momentos, assim, porque nesses momentos a gente fala um monte de coisa, cada um contribui, e leva pras suas aulas, para as nossas vidas. E que, de alguma forma, nos melhora, nos eleva, nos constrói, e permite-nos falar das diferenças e das diferentes realidades. (Joana, Instituição 1)

\section{"Um jardim de tudo e para todos" - possíveis conclusões}

Promovendo o desenvolvimento de relações interpessoais, as práticas comunicacionais propiciam interações solidárias no grupo que se vai solidificando. A experiência de grupo estimula a dimensão criadora, constitutiva e fundamental dos sujeitos, como manancial propositor de outras formas de viver e pensar, de se relacionar consigo e com os outros. As práticas comunicacionais podem ser consideradas pedagógicas quando fazem sentido a quem as propõe e a quem as realiza; quando possibilitam o desenvolvimento de inter-relações e quando permitem interlocução, questionamentos e reflexões a partir de fazeres e significados individuais e sociais presentes no grupo.

Assim, através das práticas comunicacionais vivenciadas nos recortes das três pesquisas realizadas foi possível experienciar o mundo, sensibilizar-se com ele, permitindo uma interação maior com os sujeitos e situações pesquisadas, superando o isolamento e consequentemente, construindo sentidos para os acontecimentos cotidianos na escola, em especial, e no dia a dia dos grupos envolvidos.

Desta forma, concordamos com Assmann e Mo Sung (2000, p. 256), quando afirmam que "a intensificação do desejo de entender-nos aumenta as chances de [ampliação das] interfaces comunicativas" entre os sujeitos. Assim, práticas comunicacionais com reflexão contribuem para criação de sentidos partilhados e interlocução dos sujeitos com os seus cotidianos. O diálogo, a partilha e a construção de sentidos, no ensino e em pesquisa-participante, com os professores, proporcionam reflexão, alegria e bem-estar, além de comunicação e sentimentos de pertencimento aos diferentes contextos.

Conflitos, exposições de desagrado ou mal-estar, dificuldades de atuação profissional também são situações presentes na escola, que, partilhadas em conjunto, permitem a busca de soluções e a reflexão sobre as identidades docentes nos contextos pesquisados.

Percebemos que outros sentidos foram construídos através das práticas comunicacionais. Sentidos percebidos e reconhecidos, anteriormente, conjugaramse com novos sentidos partilhados nos caminhos investigativos, que ,embora tenham sido, a princípio, propostos pelas autores-pesquisadores, tornaram-se elementos de autopesquisa para os docentes envolvidos.

Para finalizar, enfatizamos que pesquisar, ensinar e aprender sobre formação de professores é um trabalho realizado a várias mãos que se juntam para conhecer, desocultar, buscar, aproximar-se nas relações com "gente que nós conhecemos muito bem", com "gente que conhecemos um pouco e gente que a gente nunca viu e nem sabe que existe. Mas existe,em algum lugar [...]" (BRANDÃO, 2004, p. 5, grifos do autor). 
Então, fazemos das palavras de Brandão as nossas, e esperamos que nossa contribuição seja "um jardim de tudo e para todos", ou seja para todo o mundo que pesquisa, estuda e ensina para e com os professores.

\section{Referências}

ASSMANN, H.; MO SUNG, J. Competência e sensibilidade solidária: educar para a esperança. Petrópolis: Vozes, 2000.

BABIN, P. El linguaje de la nueva cultura. Madrid: Paulinas, 1993.

BRANDÃO, C. A pergunta a várias mãos: a experiência da pesquisa no trabalho do educador. São Paulo: Cortez, 2003.

BRANDÃO, C. O jardim de todos. Campinas: Autores Associados, 2004.

DAMIANI, M.; PORTO, T. M. E.; SCHLEMMER, E. (Org.). Trabalho colaborativo/cooperativo em educação: uma possibilidade para ensinar e aprender. São Leopoldo: OIKOS; Brasília: Líber Livros, 2009.

GUTIÉRREZ, F. Educacion y comunicacion en el proyecto principal. Santiago: Unesco, 1984.

GUTIÉRREZ, F. Educación e formación de personas adultas. Guatemala: MINEDUC, 2001.

GUTIÉRREZ, F. Dimensão pedagógica das novas tecnologias da comunicação e informação. In: PORTO, T.E.n (Org.). Redes em construção: meios de comunicação e práticas educativas. Araraquara: JM, 2003, p. 33-40.

PENTEADO. H. D. (Org.). Pedagogia da Comunicação: teorias e práticas. São Paulo: Cortez, 1998 .

PENTEADO. H. D. Comunicação escolar: uma metodologia de ensino. São Paulo: Salesiana, 2002.

PENTEADO, H. D. e GARRIDO, E. (Org.). A pesquisa-ensino: a comunicação escolar na formação do professor. São Paulo : Paulinas, 2010.

PORTO, T. M. E. La comunicación y la educación, una alianza necesaria en la escuela. In: CONGRESO IBEROAMERICANO DE COMUNICACIÓN Y EDUCACIÓN. [Anais do...]. Huelva/Espanha Querétaro/México, 2003.12p.

PORTO, T. M. E. As tecnologias de informação e comunicação na escola; relações possíveis, relações construídas. Revista Brasileira de Educação. v. 11, n. 31, p. 43-57, jan./abr. 2006.

PORTO, T. M. E. Pesquisa-ensino: relação universidade/escola e articulação teoria/prática In: PENTEADO, H. D.; GARRIDO, E. (Org.). A pesquisa-ensino: a comunicação escolar na formação do professor. São Paulo: Paulinas, 2010. p. 95-104.

Nota

${ }^{1}$ Os locais de pesquisa são identificados como: Instituição 1 (Escola de Ensino Fundamental); Instituição 2 (Escola de Ensino Fundamental e Médio); e Instituição 3 (Universidade Pública). Nos três locais de pesquisa, os grupos eram compostos por 10 a 20 sujeitos coordenados em separados pelos autores deste trabalho. A coleta de dados aconteceu no período de 2008 a 2010. 
* Professora Doutora da Universidade Federal de Pelotas, Pelotas, Rio Grande do Sul, Brasil.

** Professora Doutora da Universidade Federal de Pelotas, Pelotas, Rio Grande do Sul, Brasil.

*** Doutoranda do Programa de Pós Graduação em Educação - Mestrado e Doutorado da Faculdade de Educação da Universidade Federal de Pelotas, Pelotas, Rio Grande do Sul, Brasil.

\section{Correspondência}

Tania Maria Esperon Porto - Universidade Federal de Pelotas, Faculdade de Educação, Departamento de Ensino. Rua Alberto Rosa, 154, centro, CEP: 96010770 - Pelotas, Rio Grande do Sul - Brasil.

E-mail: taniaporto@terra.com.br - maristaniz@hotmail.com - lourdes.h@ig.com.br

Recebido em 09 de julho de 2013

Aprovado em 02 de abril de 2014 
